
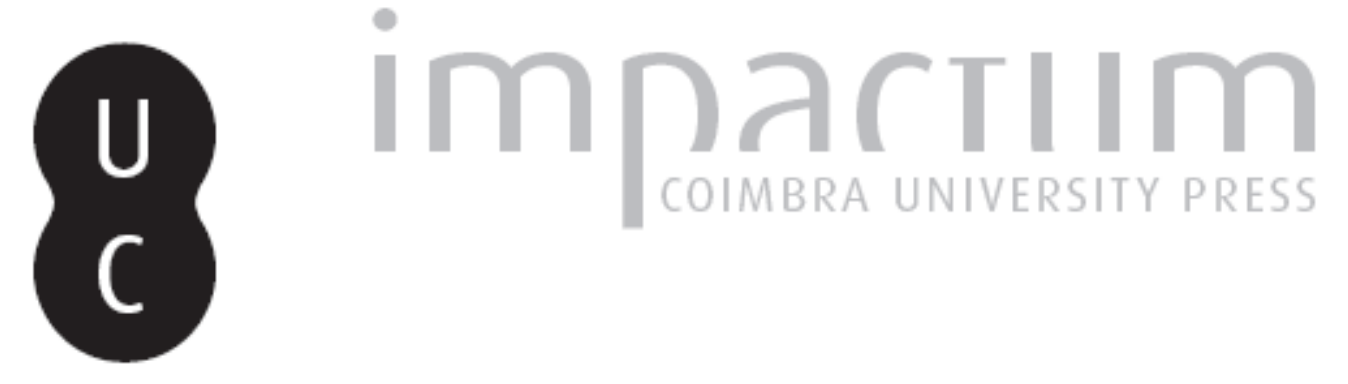

\title{
O intelectual, 0 artista e as massas na cultura portuguesa finissecular
}

Autor(es): $\quad$ Peixinho, Ana Teresa; Dias, Luís Augusto Costa

Publicado por: Imprensa da Universidade de Coimbra

URL persistente:

URI:http://hdl.handle.net/10316.2/44858

DOI:

DOI:https://doi.org/10.14195/1647-8622_18_7

Accessed : $\quad$ 26-Apr-2023 05:32:47

A navegação consulta e descarregamento dos títulos inseridos nas Bibliotecas Digitais UC Digitalis, UC Pombalina e UC Impactum, pressupõem a aceitação plena e sem reservas dos Termos e Condições de Uso destas Bibliotecas Digitais, disponíveis em https://digitalis.uc.pt/pt-pt/termos.

Conforme exposto nos referidos Termos e Condições de Uso, o descarregamento de títulos de acesso restrito requer uma licença válida de autorização devendo o utilizador aceder ao(s) documento(s) a partir de um endereço de IP da instituição detentora da supramencionada licença.

Ao utilizador é apenas permitido o descarregamento para uso pessoal, pelo que o emprego do(s) título(s) descarregado(s) para outro fim, designadamente comercial, carece de autorização do respetivo autor ou editor da obra.

Na medida em que todas as obras da UC Digitalis se encontram protegidas pelo Código do Direito de Autor e Direitos Conexos e demais legislação aplicável, toda a cópia, parcial ou total, deste documento, nos casos em que é legalmente admitida, deverá conter ou fazer-se acompanhar por este aviso.

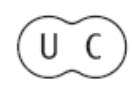




\section{ESTUDOSDOSÉCULO}

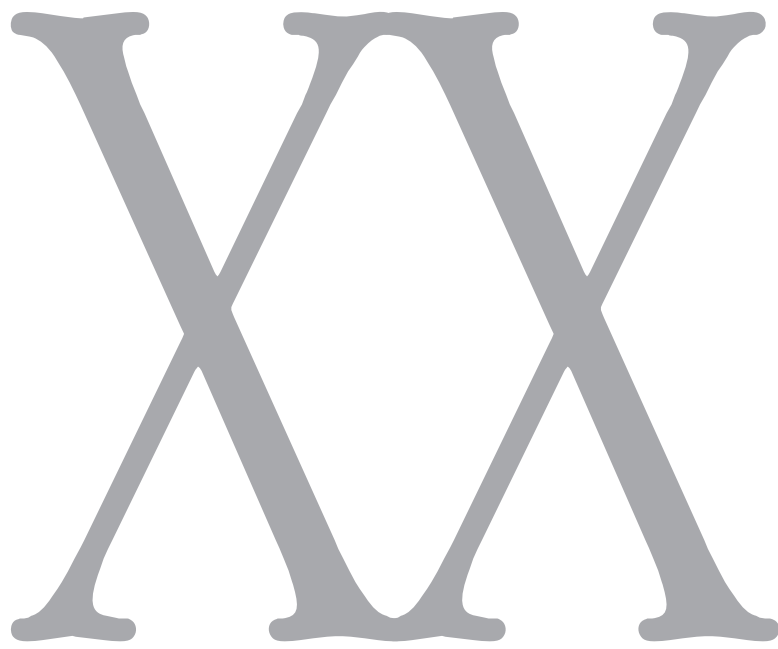

número $18 \bullet 2018$

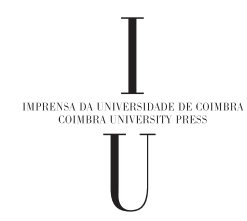




\title{
O intelectual, o artista e as massas na cultura portuguesa finissecular
}

\section{The intellectual, the artist and the masses in Portuguese culture at the end of the century}

\author{
Ana Teresa Peixinho \\ Luís Augusto Costa Dias
}

Ana Teresa Peixinho, Doutorada em Ciências da Comunicação pela Universidade de Coimbra. Investigadora Integrada do Centro de Estudos Interdisciplinares do Século XX e Investigadora colaboradora do Centro de Literatura Portuguesa da Universidade de Coimbra. Email: apeixinho71@gmail.com.

Luís Augusto Costa Dias, Doutorado em História da Cultura pela Universidade de Coimbra. Investigador do Instituto de História Contemporânea da Faculdade de Ciências Sociais e Humanas da Universidade Nova de Lisboa e da Biblioteca Nacional de Portugal. Email: lcostadias@outlook.pt. 
O INTELECTUAL, O ARTISTA E AS MASSAS NA CULTURA PORTUGUESA FINISSECULAR

Durante o século XIX, as elites cultas europeias participaram amplamente das querelas e debates fomentados na e pela imprensa, náo sendo possível fazer uma história da cultura contemporânea sem a pensar à luz da evoluçấo do espaço público ao longo desse século e na sua transiçấo para o século xx. Contudo, esta aliança entre o homem de letras e a imprensa - expediente característico da esfera pública oitocentista que, aliás, deu origem à designação de "publicista" na segunda metade do século, correspondendo a uma metamorfose do estatuto do "escritor público" do romantismo clássico - rapidamente começou a dar sintomas de rutura, à medida que aquela esfera sofria a influência da industrialização e massificação dos objetos culturais, processo iniciado nos Estados Unidos na segunda metade do século e cujo eco em França foi acompanhado de perto pela evoluçâo histórica em Portugal. Foi neste contexto conjugado, a partir do último quartel do século xix português, de alteração do mercado dos bens culturais, de emergência de uma cultura urbana de massas e de crise das elites cultas, em especial no campo literário, que lentamente surgiu a figura do "artista" como alternativa à figura difusa do "homem de letras», espoletada na última década de oitocentos. Numa leitura de Fradique Mendes - meio personagem, meio autor, proto-heterónimo na ficçáo queirosiana - e sobre o fradiquismo como ideologia, destaca-se o seu valor simbólico, como derradeira tentativa de superaçáo da morte do intelectual oitocentista através da afirmaçáo do papel do artista. Dito de outro modo, Fradique Mendes constitui-se, num contexto de massificaçáo emergente, como metáfora da crise do velho paradigma de intelectual do século xix que, perseguindo uma "aura perdida da cultura», oscila entre o silêncio de uma desistência, afinal pugnada pelo próprio Eça de Queirós que assim se revia como uma espécie de "cenobita", e a hipótese da figura do artista construir uma nova expressāo da elite culta.

Palavras-chave: Intelectual; espaço público; cultura; século xIx; Fradique Mendes
THE INTELLECTUAL, THE ARTIST AND THE MASSES IN PORTUGUESE CULTURE AT THE END OF THE CENTURY

During the 19th century, educated European elites participated extensively in the squabbles and discussions promoted in and by the press, and we cannot write the history of contemporary culture without relating it to the development of public space over that century and in its transition to the 20 th century. However, this alliance between the man of letters and the press - a typical device of the 19th century public sphere that, in fact, would give rise to the name "publicist" in the second half of the century, corresponds to a metamorphosis of the "public writer" status in classical romanticism - soon began to creak as the public sphere was influenced by the industrialisation and massification of cultural objects, a process initiated in the United States in the second half of the century, the echo of which in France was closely accompanied by the historical evolution in Portugal. It was against this combined backdrop, from the last quarter of the Portuguese 19th century, of a change in the market of cultural assets, of the appearance of a urban culture of the masses and of crisis de affecting the educated elites, especially in the literary field, that the figure of the "artist" slowly emerged as an alternative to the diffused figure of the "man of letters" triggered in the last decade of the 19th century. The reading of Fradique Mendes - half character, half author, proto-heteronym in Eça de Queiroz's fiction - and of Fradiquism as an ideology, we note its symbolic value as the last attempt to overcome the death of the 19 th century intellectual through the affirmation of the artist's role. In other words, Fradique Mendes appears, in a context of emerging massification, a metaphor of the crisis affecting the old intellectual paradigm of the 19th century, which, pursuing a "lost aura of culture", wavers between the silence of giving up, as defended by Eça de Queirós, who saw himself as a kind of "cenobite", and the chance of the artist building a new expression of the educated elite.

Keywords: Intelectual; public sphere; culture; $19^{\text {th }}$ century; Fradique Mendes
L'INTELLECTUEL, L'ARTISTE ET LES MASSES DANS LA CULTURE PORTUGAISE FINISÉCULAIRE

Au XIXe siècle, les élites européennes cultivées ont largement participé aux querelles et débats fomentés dans et par la presse et il est impossible de faire une histoire de la culture contemporaine sans penser à l'évolution de l'espace public tout au long de ce siècle et à sa transition vers le XXe siècle. Cette alliance entre l'homme de lettres et la presse, - expédient caractéristique de la sphère publique du XIXe siècle, qui donna d'ailleurs lieu à la désignation de "publiciste" dans la seconde moitié du siècle, correspondant à une métamorphose du statut d' "écrivain public" du romantisme classique - a cependant rapidement commencé à montrer des symptômes de rupture, au fur et à mesure que cette sphère était influencée par l'industrialisation et la massification des objets culturels, un processus commencé aux États-Unis au cours de la seconde moitié du siècle et dont l'écho en France a été suivi de près par l'évolution historique au Portugal. C'est dans un contexte conjugué, à partir du dernier quart du XIXe siècle portugais, de changement du marché des biens culturels, d'émergence d'une culture de masse urbaine et de crise des élites cultivées, en particulier dans le domaine littéraire, qu’a lentement émergé la figure de l'"Artiste» comme alternative à la figure diffuse de "l'homme de lettres", déclenchée au cours de la dernière décennie du XIXe siècle. Dans une lecture de Fradique Mendes - mi-personnage, mi-auteur, protohétéronome dans la fiction de Queirós - et concernant le "fradiquismo" comme idéologie, nous soulignons sa valeur symbolique comme ultime tentative de surmonter la mort de l'intellectuel du XIXe siècle grâce à l'affirmation du rôle de l'artiste. En d'autres termes, Fradique Mendes s'assume, dans le contexte de massification, comme une métaphore de la crise du vieux paradigme intellectuel du xixe siècle qui, poursuivant une "aura perdue de la culture», oscille entre le silence d'un abandon, soutenu, d'ailleurs, par Eça de Queirós lui-même, qui se revoyait ainsi comme une sorte de "cénobite», et l'hypothèse de la figure de l'artiste pour construire une nouvelle expression de l'élite cultivée.

Mots-clé: Intelectuel; espace publique; culture; $\mathrm{XIX}^{\mathrm{èm}}$ siècle; Fradique Mendes 


\section{Homens de letras e espaço público}

Durante o século XIX, as elites cultas europeias participaram amplamente das querelas e debates fomentados na e pela imprensa, não sendo possível fazer uma história da cultura contemporânea sem a pensar à luz da evolução do espaço público ao longo desse século e na sua transição para o século xx, isto é, em última instância, integrando o cultural no social. Tais elites não só promoviam as suas publicaçóes no espaço impresso, como a própria dinâmica do debate público se nutria de cartas, panfletos, textos escritos e publicados por esses mesmos agentes culturais (PEIXINHO 2011).

Contudo, esta aliança entre o homem de letras e a imprensa - expediente característico da esfera pública oitocentista que, aliás, deu origem à designação de "publicista» na segunda metade do século, correspondendo a uma metamorfose do estatuto do «escritor público» do romantismo clássico, segundo expressão de Garrett (DIAS 2014a: 1114-17) - rapidamente começou a dar sintomas de rutura, à medida que aquela esfera sofria a influência da industrialização e massificaçáo dos objetos culturais, processo iniciado nos Estados Unidos na segunda metade do século (BALLE 1997: 76-77) ${ }^{1}$. Embora, em Portugal, esse cenário seja um pouco mais tardio e de penetração mais lenta (DIAS 2014b: 370-373) ${ }^{2}$, não deixa de ser verdade que os nossos intelectuais oitocentistas deram múltiplos sinais de constrangimento face às transformaçóes do espaço público. O alargamento dos públicos, a abertura às massas, a importação de fórmulas feitas e rentáveis para a imprensa foram fatores que, progressivamente, empurraram ainda mais para as margens do campo impresso esses homens de letras, alargando a territorialidade do jornal e cedendo a novos produtos culturais mais acessíveis, apelativos e, no retorno, lucrativos (PEIXINHO 2013: 192).

A imprensa de massas, como explica João Carlos Correia, «chama a si conceitos novos que até aí eram na sua maioria desconhecidos pelo jornalismo de opinião: mais do que a urgência ideológica da mensagem veiculada contava a sua atualidade, isto é, o seu caráter de acontecimento novo, tendencialmente inesperado e recente; mais do que a mobilização dos leitores para uma cruzada, importava proporcionar-lhes informaçôes sobre o mundo que fossem simultaneamente úteis e agradáveis, ou seja, suscetíveis de serem consumidas.»(CORREIA 1998: 94-95) Face a estas mudanças, escritores e jornalistas europeus, formados numa arreigada tradição histórica segundo a qual literatura, política e jornalismo viviam numa harmoniosa comunhão, recusaram em geral ceder à incomodidade causada por essa massificação ${ }^{3}$.

\footnotetext{
${ }^{1}$ Falamos do auge da imprensa de massas, cuja eclosâo se fica a dever à convergência de inúmeros fatores, entre eles os progressos técnicos que permitiram uma revolução do impresso, em particular na capacidade das tiragens, a expansão da instrução que potenciava o número de leitores, sobretudo nos meios urbanos, e a consequente massificação do público que levava a uma forte concorrência entre as publicaçóes e ao recurso a estratégias comerciais que influenciavam tanto os formatos como as linguagens e os conteúdos.

${ }^{2}$ Se 1836 foi, em França, o ano I da era mediática, com o aparecimento de La Presse de Girardin (THÉRENTY; VAILLANT 2001), só em 1864 apareceria o Diário de Notícias como fenómeno equivalente (MIRANDA 2002). Todavia, quando falamos da decisiva entrada na era mediática, no último quartel do século XIX, a realidade portuguesa segue já de perto a francesa (DELPORTE 1999; KALIFFA 2001).

${ }^{3}$ José-Luis Diaz mostra como Balzac, em Monographie de la Presse Parisienne, denunciou alguns vícios do jornalismo, como o industrialismo, o arrivismo, o cinismo, a sujeição ao poder e ao dinheiro, etc. (conjunto de defeitos que o romancista já havia abordado em romances como Un grand homme de province à Paris e
} 
Uma das características identitárias da imprensa portuguesa moderna é precisamente o estreito vínculo estruturante ao campo literário, ao longo de todo o século XIX, à semelhança do que sucedeu em França (CHALABY 2003; PEIXINHO 2013). Antes da autonomização da profissão de jornalista, para os finais de Oitocentos, os jornais eram dirigidos e redigidos em grande parte por homens de letras (escritores propriamente ditos ou figuras do campo cultural a eles ligados) que viam na imprensa um meio de conquistar público e de compensar o parco sustento conseguido com a venda dos livros, num espaço editorial muito limitado pelo menos até ao último quartel do século, altura em que teve início no nosso país a Era dos Editores modernos, distinta do heroico Mundo dos Livreiros, coincidindo com o aparecimento do jornalismo de massas (DIAS 2017). Porém, diversas vozes se levantaram contra esta relação entre o campo literário e os jornais, considerada perversa para a qualidade estético-literária das publicaçôes, antes de mais por cercear a liberdade intelectual dos escritores, submetendo-os às novas lógicas do mercado cultural que se sobrepunham ao elitismo seletivo e à desejável independência que uma produção artística deveria exigir.

Já no contexto finissecular em que vamos particularmente incidir ${ }^{4}$, a leitura de uma das cartas ficcionais de Fradique Mendes, endereçada "A Bento de S." - texto que, aliás, resultou do reaproveitamento de uma crónica já antes publicada pelo próprio Eça de Queirós na Gazeta de Notícias ${ }^{5}$ - legitima a defesa de um certo ideal de imprensa que entendia incompatível com a massificação e a industrialização dos jornais, uma imprensa que deveria ainda contar com os homens de letras, num quadro em que o estatuto intelectual estava em crise no final do século. Assim se entende que Eça tenha emprestado à pena desse seu proto-heterónimo (o cético elitista e dândi Fradique Mendes) as mesmas críticas que o escritor então subscreveu sobre o jornalismo. Se atentarmos na ampla e acesa discussão que envolveu os intelectuais franceses no fim do século, perceberemos que a visão crítica de Eça de Queirós, dispersa nas suas crónicas de imprensa, não é isolada nem original ${ }^{6}$. Mas há toda uma originalidade na criação dessa figura ficcional - meio personagem, meio autor - e na importância simbólica que resulta da estratégia ideológica construída pelo fradiquismo.

\footnotetext{
Illusions Perdues, em que compôs um quadro pessimista do panorama do jornalismo da época): "l'écriture automatique qu'engendre la press est, selon lui, une trahison de l'originalité littéraire, qualité suprême aux yeux des romantiques." (DIAZ 2005: 31-50). A propósito de Illusions Perdues, Ruth Rodríguez Martínez insiste: "Una de las causas de la visión crítica que tuvo Balzac del periodismo se debe en gran medida a la convicción de que el trabajo periodístico degrada, agota el ingenio y distrae del ejercicio literario." (RODRÍGUEZ MARTÍNEZ 2006: 450).

${ }^{4}$ Tomamos essa aceçáo de arrastamento das tendências finisseculares nos princípios do século seguinte, estudada, por exemplo, por José Carlos Seabra Pereira (PEREIRA 1999; 1995).

${ }^{5}$ Inicialmente publicada na Gazeta de Notícias em 26 a 28 abr. 1894, saiu finalmente na Revista Moderna em 25 jul. 1897 e ainda, segundo Guerra da Cal, reeditada no Jornal do Comércio em 2 out. 1897 (QUEIRÓS 2014: 307-316).

${ }^{6}$ Segundo Thomas Ferenczi, entre 1897 e 1898, a Revue Bleue desenvolveu um largo debate sobre o papel da Imprensa, em que se destacaram duas conceçóes antagónicas de jornalismo: uma conceção de matriz pedagógica que entendia o jornalismo como uma prática com deveres públicos e edificantes, capaz de traduzir ideias e defender princípios, por um lado; por outro, uma conceçáo mais moderna e consentânea com as inovaçóes importadas do jornalismo americano, que colocava a ênfase na vertente lúdica e lucrativa do jornal.
} 
Não esqueçamos, porém, que, em 1841, António Feliciano de Castilho, no programa da Revista Universal Lisbonense em que o poeta se revelou interessante cronista do quotidiano (VENÂNCIO 1995), embora reconhecendo uma prevalecente missão educativa e pedagógica do jornal, não escondia já alguma desconfiança:

Este século, tão destruidor como criador, matou a Livraria, e pôs no seu lugar o Jornalismo. Assim devia ser, porque este século é popular. Os livros eram a muita ciência para poucos homens; os jornais são um pouco de pouca ciência para todos (apud SANTOS 1985: 165$)^{7}$.

Opiniốes como esta inscrevem-se numa discussão de maior latitude que, a partir dos meados do século, ocupou o universo dos escritores e que se prende com a tensão criada pelo aumento exponencial do público leitor e pela sujeição a novas regras de mercado. Notemos também que, quando da discussão de legislação sobre propriedade literária, em 1851, a voz cética de Alexandre Herculano se insurgiu contra aquilo que ele considerava ser a prostituiçáo do escritor e a consequente perda de qualidade da obra (HERCULANO 1982: 233) ${ }^{8}$. O que estava em causa era, por um lado, a manifestação de resistência do homem de letras que, cedo, percebeu que a evoluçáo do mercado, bem como o alargamento do público, que rapidamente acarretariam consequências sérias para a qualidade artística das obras e para o estatuto tradicional do intelectual; por outro lado, a cultura deixava progressivamente de estar reservada a uma elite restrita e, ampliando-se a todos os que franqueavam essa porta da cultura, descia da torre de marfim para as ruas. Cedo, portanto, Herculano reagia à mudança de paradigma que se anunciava a partir do momento em que os bens culturais passariam a ser necessariamente mediados. Pois, como acentua Christophe Charle: "A imprensa é, com efeito, a mediação essencial entre essas mutações culturais e sociais e as transformaçóes, a diversos níveis, na produção literária.” (CHARLE 1979: 47) Porém, a fratura entre literatura e jornalismo, que começou a dar sinais pelos meados do século, tornou-se particularmente visível no seu último quartel (PEIXINHO 2013: 203-204).

Quase no final do século, numa carta-prefácio à obra Azulejos do Conde de Arnoso, Eça de Queirós alargava-se em interessante reflexão sobre as novas tensóes que regiam a relação entre o escritor e os seus novos públicos, constatando que o aparecimento de "uma multidão azafamada e tosca que se chama o 'público"” vinha alterar radicalmente o papel do "homem de letras» num campo cultural em rápido crescimento e diversificação. Foi este o diagnóstico:

\footnotetext{
${ }^{7}$ A citação de Castilho foi retirada do programa da Revista Universal Lisbonense, publicado em $O$ Recreio, n. ${ }^{\circ}$, agosto de 1841 (SANTOS 1985: 261). O «século popular» de Castilho compagina-se com a noção romântica também inscrita por Almeida Garrett na fórmula «século democrático», ao apresentar o drama Frei Luís de Sousa, em 1844, com a memória "Ao Conservatório Real»: em meados do século, o "povo» era, no fundamental, a classe média proprietária, instruída e politizada (DIAS 2010: 85).

${ }^{8}$ Embora por motivos conservadores que o opunham à novidade da legislação sobre direitos de autor, da lavra de Almeida Garrett, Herculano assinalava o espectro do que designava por «literatura-mercadoria» ou «literatura-agiotagem» e o perigo de com elas se corromperem os "ministros» da verdadeira "religiāo» pública que «são os homens de letras ou de ciência».
} 
Essa coisa tão maravilhosa, de um mecanismo tão delicado, chamada o indivíduo, desapareceu; e começaram a mover-se as multidóes, governadas por um instinto, por um interesse ou por um entusiasmo. Foi então que se sumiu o leitor, antigo leitor, discípulo e confidente, sentado longe dos ruídos incultos sob o claro busto de Minerva, o leitor amigo, com quem se conversava deliciosamente em longos, loquazes «Proémios»: e em lugar dele o homem de letras viu diante de si a turba que se chama o público, que lê alto e à pressa no rumor das ruas (QUEIRÓS 2009: 189).

\section{Fradique Mendes e a metáfora da desistência}

A lucidez destas consideraçóes, reveladoras, antes de mais, da aguda consciência que o escritor tinha do seu tempo, nomeadamente do contexto cultural em que vivia, permite ilustrar o que temos vindo a descrever: no último quartel do século xIx, o «homem de letras» - velho guardiáo da cultura - percebeu com acuidade que o amplo movimento de mediação desencadeado pela erupção da imprensa industrial veio revolucionar o campo cultural, cindindo-o. O leitor foi substituído pelo público; a relaçáo intimista entre autor e leitor passou a ser aberta e mediada; a leitura perdeu a dimensão de recolhimento e a rua, o café, a esplanada e o parque passaram a ocupar o lugar, outrora privilegiado, da livraria... ${ }^{9} \mathrm{O}$ resultado, segundo Eça de Queirós reproduzia de uma pretensa carta de Fradique a Carlos Mayer, era a «camada de Lugar-Comum» que ao público, «todos os dias, através da vida, o Jornal, a Revista, o Folheto, o Livro lhe vão atochando no espírito até lho empastarem todo em banalidade» (QUEIRÓS 2014: 143).

E o escritor? Restava-lhe, em geral, perseguir uma «aura perdida da cultura» que Eça apontou "como uma consolação e uma esperança» do seu Fradique Mendes (id.: 197), o pretenso poeta de umas Lapidárias juvenis que entretanto se entregou a «um tão constante e claro propósito de abstenção e silêncio» (id.: 189). Para o assunto que nos interessa, Fradique deve ser lido como metáfora da crise de estatuto intelectual em final de século, remetido o homem de letras a uma atitude de desistência seletiva e blasée. Neste sentido, A Correspondência de Fradique Mendes criada por Eça de Queirós pode ser vista como peça fundamental do processo final de esgotamento da figura de intelectual que dominou o longo século XIx.

Não muitos anos após, foi Sampaio Bruno, um dos mais representativos intelectuais desse século, quem assinou, na introdução a um seu ensaio sobre Os Modernos Publicistas Portugueses, já em 1906, a derradeira peça desse processo que arrastou a "crise finissecular» para os inícios do século seguinte, com um olhar nostálgico para a sua pena de escritor (na forma de interrogaçóes que a si mesmas se respondem):

Olho para a minha pena. Trouxe-me ela a riqueza, a posição definida, a independência, a fortuna, a rutilância social, as consideraçóes sociais? Granjeou-me o descanso para meus

\footnotetext{
${ }^{9}$ Ainda sem publicação, Luís Augusto Costa Dias abordou recentemente as condiçôes históricas de formação de uma "cultura de rua" em La calle y la "masa semiletrada": reconstitución de itinerarios populares en la transición del siglo XIX al XX. Seminario Anual De la casa a la calle: lugares, usos y apropiaciones de la cultura escrita (siglos XVI-XX), Universidade de Alcalá de Henares, 2017.
} 
velhos dias, a segurança na vida? Libertou-me da apreensão do amanhã? Favoreceu-me com a tranquilidade de espírito, indispensável (se delas fosse capaz) às cogitações altas e desinteressadas, que, honrando o cismador, dignificam as sociedades e enobrecem as literaturas? Conquistou-me a amizade dos meus patrícios, a estima de meus concidadãos? (BRUNO 1906: XIX-Xx).

Ora, a construção de Fradique Mendes, tributária de tendências e fontes muito diversificadas, até por vezes antagónicas, como sublinham muitos dos estudiosos de Eça de Queirós, produz um efeito de «montagem intencional» (LIMA 1987: 338), capaz de traduzir o seu espírito como uma "colcha de retalhos» (MOSER 1945: 391). Personagem compósita, portanto, complexa, construída com elementos de proveniência muito diversa, aponta, antes de mais, para as características físicas e intelectuais de alguns membros da Geraçáo de 70, tal como se apresentaram na década de oitenta, com quem Fradique comunga do mesmo espaço e tempo culturais e com os quais afirma ter-se correspondido ${ }^{10}$. Porém, como ideologia, a que se tem chamado fradiquismo, estamos perante um conjunto de ideias que se nos afiguram muito importantes no contexto finissecular português, devedoras da aguda crise de valores que marcou esse tempo, prolongando-se no início do século seguinte, conforme viu Lourenço: «Se identificamos o Fradiquismo já não com a ideologia particular de uma personagem de ficção criada por Eça de Queirós mas com uma ideologia de algum modo representativa de uma época, verificamos que esta perdura após o desaparecimento da Geração de Eça penetrando de forma decisiva no século xx.» (LOURENÇO 1986: 47-48)

Quer isto dizer, portanto, que $A$ Correspondência de Fradique Mendes encerra uma ideologia que, não sendo alheia à evolução do seu autor, não deixa também de dialogar com o tempo em que se integra. Já Guerra da Cal afirmara: «Fradique é a encarnação abstrata, e impossível, dum ideal de época, e mais concretamente do ideal da Geração de Eça. Um super-homem estético, levemente atingido pela abulia requintada do 'mal du siècle', que 'flirtou' com a ideia de escrever uma Teoria da Vontade." (CAL 1994: 350). Seguindo este raciocínio, a criação de Fradique Mendes, por Eça de Queirós, vem responder à necessidade sentida pelo autor de promover uma entidade capaz de projetar novos valores, tanto ideológicos como estéticos. O ecletismo errante, o pessimismo inquietante, o ceticismo irónico, a desistência, o individualismo e um certo dandismo aristocrático são marcas de Fradique Mendes que projetam um conjunto de atitudes dos intelectuais finisseculares, transformando a criação queirosiana numa «ilustração quase programática de um conjunto de valores» típico da modernidade (PIEDADE 2003: 283).

Fradique é composto por Eça como a figuração de um ideal, através de um conjunto de atributos que o transformam, mais que num tipo, em arquétipo. Junte-se-lhe a excentricidade, a aura de mistério, a tópica das viagens, o gosto requintado e excêntrico, a sofisticação da toilette; enfim, características físicas e psicossociais que o elevam a um patamar quase sobre-humano, como se ele fosse, antes que tudo, uma utopia:

\footnotetext{
${ }^{10}$ Diversos estudiosos comungam desta opinião, lendo Fradique como um símbolo da desapontada Geração de 70 que, no final do século, se autointitula de Vencidos da Vida (MOOG 2006: 272; LIMA 1987: 336; MONTEIRO: 222).
} 
"falava a língua dos deuses; recebia deles a inspiração.» (QUEIRÓS 2014: 116) Era a utopia da recuperação do restrito espaço de uma elite que o homem de letras havia perdido pela abertura do campo cultural, tanto à rua e ao público como, sobretudo, ao número crescente de agentes no campo literário e, entre eles, os intelectuais reunidos nessa ampla designação de "publicistas", numa pirâmide em cuja base estavam os recém-chegados e em cujo topo se tornavam proeminentes figuras que acumulavam o alarde regular na imprensa com a intriga nos partidos, a exibição parlamentar, o assento no governo, as açóes nas companhias, os empregos públicos, o reconhecimento nas Academias e a aura diletante. Mariano de Carvalho, fundador do Diário Popular, em 1868 , por onde entrou na notoriedade pública como "publicista», foi um caso limite de exemplar sucesso dessa figura ou estatuto (FERNANDES 2010); e neste exemplo poderia o nosso Fradique Mendes estar a pensar quando visava os «homens de letras, esticados nas gravatas e nas ideias que toda a Europa usa», com destaque para o ódio ao «tipo uniforme (representado pelo sujeito utilitário e sério de sobrecasaca preta)» (QUEIRÓS 2014: 162).

Ora, se à construção plástica de Fradique falta vida e humanidade, é, por isso, muito mais do que uma personagem, afirmando-se como uma existência figurada capaz de transportar uma ideologia com a qual o Eça autor tenta um diálogo virtual, sem no entanto o levar às últimas consequências. $\mathrm{O}$ adiamento do projeto heteronímico e as hesitaçóes que conduziram o autor a protelar a publicação de $A$ Correspondência de Fradique Mendes são até fatores sintomáticos de um tempo de charneira e de transição, em que o intelectual procurava ainda um novo estatuto para a elite ${ }^{11}$. Aliás, este valor representativo de Fradique Mendes está intimamente ligado ao processo de amadurecimento intelectual e estético do seu criador, pois que, como é sabido, a partir da década de oitenta, Eça de Queirós entra num processo de revisão de valores que o afasta progressivamente da ideologia de índole positivista e da estética naturalista, numa busca de novos caminhos estético-ideológicos ${ }^{12}$. Fradique, portanto, é um projeto de escritor ou "artista» (de pena) que, apesar de ter biografia, nome e ideias, nunca chega a publicar-se, ficando "para sempre inédito e mudo", como comenta o narrador. Para Fradique, a escrita tornara-se perfeitamente inútil, não apenas porque duvidasse da utilidade e validade das suas ideias, mas sobretudo porque, como o próprio afirma: «Eu não sei escrever! Ninguém sabe escrever!»

\footnotetext{
${ }^{11}$ Inclinamo-nos a sustentar, numa perspetiva analítica em vias de exploração, que a designação de "geração", que a si mesmos deram, prolongadamente, os intelectuais agrupados nas Conferências do Casino de 1870 , representou um estatuto «intermédio» na genealogia das elites intelectuais de que adiante falaremos (cf. CHARLE 1990: 24 ss.).

${ }^{12}$ Ora, segundo alguns estudiosos, nomeadamente Carlos Reis, Fradique Mendes deve entender-se à luz deste contexto de revisão de valores, característico daquilo que é comum chamar-se o último Eça: «Por agora, Fradique interessa-me como estratégia literária de feição anti-realista: figura pré-heteronímica e não personagem de romance, Fradique significa, como estratégia literária, algo mais do que o Carlos da Maia com quem mantém afinidades ideológicas. O que ele traz à cena literária queirosiana é uma voz outra, claramente autonomizada em relação a Eça; com ela, advém o implícito reconhecimento da impossibilidade (estética e também ética) de reduzir a escrita literária a uma poética de certa forma fechada como era a do Realismo.» (REIS 1999: 159).
} 
Nem mesmo as grandes referências literárias passadas e contemporâneas - explicitamente Bossuet, Beaumarchais, Hugo, Taine, Balzac ou Flaubert - escapam ao estreito e utópico crivo fradiquiano que anseia, na escrita, afinal, por

[...] alguma coisa de cristalino, de aveludado, de ondeante, de marmóreo, que só por si, plasticamente, realizasse uma absoluta beleza - e que expressionalmente, como verbo, tudo pudesse traduzir desde os mais fugidios tons de luz até os mais subtis estados de alma... (QUEIRÓS 2014: 187)

Distantes estamos, portanto, da conceção utilitarista e militante da literatura realista (mais ainda da conceção romântica do poeta cidadão a que faremos adiante referência); Fradique assumia agora a defesa impossível de um parnasianismo levado ao extremo, não sem uma costela decadentista, acabando mesmo por reconhecer a incapacidade de a linguagem traduzir o real ou o belo:

Só se podem produzir formas sem beleza: e dentro dessas mesmas só cabe metade do que se queria exprimir, porque a outra metade não é redutível ao verbo. (id.: 188)

Perante a inexistência de obra (sintomaticamente enterrado o "poeta» que Fradique fora na sua juventude), o narrador-biógrafo toma a decisão de publicar o único legado fradiquiano que estaria ao seu alcance: as suas pretensas cartas particulares, entendidas como «leves migalhas desse ouro de que fala Alceste e onde se sente o brilho, o valor intrínseco, e a preciosidade do bloco rico a que pertenceram.» (id.: ibid.) Quer isto dizer, portanto, que, desfrutando destas características, o discurso fradiquiano assume-se, assim, náo como o discurso acabado e fechado de uma voz autoritária e definitiva, mas antes como o resultado de um pensamento em construção, relativamente ao qual o próprio não tinha nem certezas nem grandes expectativas. Como intelectual cético e extremamente crítico, mesmo em relação a si mesmo, Fradique Mendes não acreditava, como dissemos, no valor definitivo das suas ideias, nem publicava por considerar que náo acrescentaria, com a sua obra, nada que valesse a pena, atitude sintomaticamente caracterizada por alguns autores como uma "hibernação" (DIOGO; SILVESTRE 1993: 103).

Recordemos, contudo, que é o próprio Fradique a legitimar a publicação das correspondências como forma de perpetuar as ideias de um homem; e, ao fazê-lo, apresenta como principal argumento o facto de, nelas, o "valor das ideias» ser decidido por terceiros e não pelos sujeitos de escrita (QUEIRÓS 2014: 190-191). Desta forma, ao decidir apresentar publicamente esse homem de letras através do seu epistolário, Eça de Queirós desencadeia uma dupla mistificação: não só responsabiliza uma entidade discursiva pela revisão de ideias e valores que ele próprio não assumia, como o faz por meio da publicação póstuma e parcelar, com tudo o que ela representa de inacabado, fragmentário e provisório. Por outro lado, dispensando o "revestimento» literário, as cartas situam-se num espaço de marginalidade requintada e esteticizante que combina com a figura de Fradique. Um homem diferente, profundamente crítico relativamente à massificação das sociedades modernas gerada «nestas Democracias industriais e materialistas» em que «as almas cada dia se tornam mais secas» (id.: 174), situado na 
charneira entre dois tempos e dois séculos, requintadamente aristocrático e dândi, Fradique tem da esfera literária e do campo cultural uma imagem extremamente disfórica e desiludida, chegando mesmo a simbolizar "o homem de letras em estado de nostalgia irremediável»(DIOGO; SILVESTRE 1993: 107).

Quando, no final do século XIx, Eça de Queirós se dedicou ao projeto de Fradique, incompleto e inacabado pela morte prematura do escritor, estava longe de imaginar (ou talvez náo) o valor simbólico que aquela sua figura traria para a cultura portuguesa na viragem do século. Mais do que uma personagem queirosiana, Fradique Mendes é a figuração de um certo ideal, utópico e abstrato, do intelectual oitocentista finissecular, a braços com a aguda crise do seu estatuto simbólico e perante as transformaçóes profundas do espaço público português. A modernidade desta criação representou, simultaneamente, a defesa tipicamente finissecular de um esteticismo como «a suprema liberdade junta à suprema audácia» (QUEIRÓS 2014: 141) e, portanto, a reclamação do estatuto de artiste (sublinhado pelo próprio autor) que opunha, a esses «tempos de abstrata e cinzenta intelectualidade, a religiâo verdadeira da Linha e da Cor!» (id.: 117)

Trata-se do artista, fosse ele artista de pena ou de pincel, criador apenas de beleza plástica, desvinculado de qualquer compromisso ou utilitarismo; por isso, ao final, acabava por desconfiar da eficácia que o "escritor e criador duma Prosa, que só por si própria, e separada do valor do pensamento, exercesse sobre as almas a ação inefável do absolutamente belo» (id.: 184). As cartas de Fradique representam precisamente um testamento - errante, disperso e assistemático, como «a distância mais curta entre dois pontos é uma curva vadia e delirante!» (id.: 141) - do intelectual oitocentista em crise de estatuto simbólico, cujo último reduto seria a desistência compaginável, no caso de Fradique, com a atitude de elitismo snobe e desinteressado, remetido em flâneur a que mais não restava que ser «um homem que passa, infinitamente curioso e atento.» (id.: 147)

\section{Uma genealogia sumária do «poeta» ao «artista» de Oitocentos}

Não obstante a admiração que Fradique Mendes afirma desde jovem nutrir por "Victor Hugo, a quem chamávamos já "papá Hugo" ou "Senhor Hugo Todo-Poderoso" [que] não era para nós um astro - mas o Deus mesmo, inicial e imanente, de quem os astros recebiam a luz, o movimento e o ritmo» (id.: 80 ) - essa figura profética do poeta romântico não passava já, então, de um vento soprado do passado. Tal como, aliás, fora para o próprio Eça, nos tempos juvenis, o grande romântico português: "Garrett tinha-se separado de nós, tomando pelo atalho que leva a Deus, e legando à geração presente a pouca alma que ela ainda tem.» (QUEIRÓS 2009: 89)

A figura do poeta que se fez cidadão ${ }^{13}$, combatendo como arauto das grandes causas públicas, esgotara-se em meados do século. Se o combativo escritor Rodrigues Sampaio, ao cabo das lutas liberais (isto é, no seu epílogo, com a impossibilidade derradeira do liberalismo se concretizar na rua, representada pelo desfecho do episódio patuléu),

${ }^{13}$ A expressão em itálico pertence a Garrett, no prefácio (verdadeiro manifesto) à sua Lírica de João Minimo, em 1828; num outro prefácio, igualmente doutrinário, ao tomo I do romance O Arco de Santana, em 1845, temia já o ocaso simbólico desses "poetas - grandes profetas e grandes missionários do século». 
admitia em 1847 que «já não temos objeto que defender, nem inimigo a quem atacar», convidava então: "Cidadãos, toca a ensarilhar armas e a descansar!» ${ }^{14}$ De outro modo, mas no mesmo tom, António de Serpa (irmão do dramaturgo e também poeta Serpa Pimentel) declarava, em 1851, no epílogo à leitura das suas Poesias, o que considerava já «repetir uma banalidade», isto é que «a época não vai poética» (SERPA 1851: 226).

Com efeito, instalara-se uma "quadra adormecida» onde, segundo ainda acrescentava Lopes de Mendonça em 1852, «nenhum acontecimento notável inspiraria a imaginação dos poetas» (MENDONÇA 1855: 22). E com o fim dessa época, a figura do "poeta» - que para si tomara a missáo de escritor público, com o objetivo militante de formar uma opinião pública de burgueses cultos, proprietários e intervenientes (GARRETT 1990), numa esfera política definida à partida por regras censitárias - esse poeta perdeu o seu valor simbólico na segunda metade do século XIX... salva a sobrevivência tardia em Guerra Junqueiro, enfim saudado nos primeiros anos do século seguinte como "profeta da república». O próprio Antero de Quental era, nessa altura, mais «santo» que poeta, representava o «sábio». Enfim, certamente por considerar incapaz de resgatar-se, em fim de século, essa figura visionária do poeta, o Fradique Mendes queirosiano despiu definitivamente a roupagem poética.

A partir de meados de Oitocentos, a atividade dos poetas fixou-se no domínio da língua, do estilo, da retórica, com os seus tratados, polémicas e sociedades de «elogio mútuo»; e, no lugar que outrora o "poeta» ocupara na praça pública, veio a instalar-se na tribuna da imprensa uma outra figura que Camilo Castelo Branco, já em 1849, intuía sarcasticamente destinada a adquirir uma presença duradoura:

O folhetinista é a essência da literatura do século - é a expressão mais simples, quero dizer, é a parte volátil, diáfana, palpitante, que se ergue deste cadinho onde fervem as inteligências ao lume da regeneração intelectual (BRANCO 1924: 474).

A figura do folhetinista não constituiu propriamente um estatuto simbólico, certo, mas ajuda-nos a perceber o alargamento do campo intelectual oitocentista e como a corrida à oportunidade de exibição em público, através da crónica social, política ou literária, contribuiu no limite da figura do publicista para um "cinismo carreirista» por parte de alguns homens de letras (CHARLE 2001: 161). Não obstante não ser este o lugar para desenvolver a questão, o assalto a uma presença no espaço público derivou de inúmeras causas: antes de mais, a diversidade de formação intelectual, num mundo que até meados do século fora domínio dos homens de leis e passava a ter homens de letras oriundos das novas escolas superiores e técnicas (lentamente saídas das reformas de Passos Manuel), engenheiros de diversas especialidades, médicos, professores, enfim jornalistas, e, já para o último quartel do século, o aumento dos autodidatas de extração pequeno-burguesa que, além de um crescimento das profissóes intelectuais, ampliaram o universo das letras e das artes. Neste cenário, o folhetinista constituiu uma figura que depressa se confundiu não tanto com o que publicava prosa narrativa (ou a tradução de alheia, que a partir de então também se vulgarizou) como, num sentido mais amplo, com todo aquele que tomou a tribuna da imprensa

${ }^{14}$ [Rodrigues Sampaio: «Editorial»]. O Espectro. Lisboa: s.n., 63 (3 jul. 1847). 
para se afirmar no espaço público sob a designação genérica de "publicista». Foi o que Luciano Cordeiro identificou quando, em 1869 - num campo intelectual em que cresciam «renomes que todos sabem como se hão feito entre nós, modernamente, tantos e tantos» -, apontou o caso de Pinheiro Chagas como «medíocre romancista, não melhor poeta e detestável crítico» cuja saída estava «no folhetim [que] é onde mais distintamente poderá conservar-se.» (CORDEIRO 1869: 234)

Esta foi a época de explosão da imprensa portuguesa: só nas duas décadas finais do século xix, publicou-se quase 55\% dos títulos periódicos criados em toda a centúria; e, se a essas juntarmos as duas décadas imediatamente anteriores, o número de jornais, revistas e outras folhas periódicas criadas entre 1861 e 1900 corresponde a mais de $78 \%$ do total publicado nesse século (DIAS 2017). A entrada de Portugal na era mediática situa-se entre 1865 e 1867, quando o número de publicaçóes ultrapassou em média os 50 títulos fundados por ano em todo o país; foi então que surgiram os grandes jornais diários com tiragens de largos milhares e a baixo preço por número, isto é imediatamente posterior à saída do Diário de Notícias, em 1865. Esta «era dos jornais», que teve no "império d'O Século» o momento decisivo, foi um fenómeno que se compagina com uma fase de crescimento dos principais centros urbanos, nomeadamente nos níveis de acesso à leitura por parte de uma população que já não era apenas burguesa e tocava as franjas populares no acesso aos objetos de cultura: por volta de 1880 , o recenseamento da população urbana portuguesa situada num eixo litoral atlântico registava índices que rondavam 50\% dos indivíduos residentes nas cidades com capacidade de leitura (DIAS 2014b: 370-373). Os intelectuais da época acompanharam (ou seguiram) esta explosão da imprensa de massas que lhes permitia um lugar de relevo público, sendo claro que a entrada no vértice superior das elites da época, incluindo a elite do poder, se fez em grande parte pela porta da cultura.

Sem um tipo de intelectual concorrente do "poeta», até então, o "publicista» constituiu uma metamorfose do «escritor público» (DIAS 2014a: 1114-17); adquiriu um novo capital simbólico publicando, com ou sem talento, mas compulsivamente, insistentemente, na imprensa da época e, granjeando desse prestígio público, fez a sua entrada numa ou em várias academias e associaçóes reais, ao mesmo tempo que se acercou das elites políticas e com elas se confundiu e acedeu ao poder ${ }^{15}$. Pinheiro Chagas, já que acima falámos nele, foi justamente um dos exemplares típicos desse publicista: com formação na Escola Politécnica de Lisboa, cedo trocou a carreira militar pelo investimento nas letras, cumprindo o percurso do publicista encartado que o conduziu do jornalismo ao caciquismo partidário, ao parlamento em sucessivas legislaturas, finalmente ao ministério na pasta cuja política colonial conduziria ao chamado «ultimatum inglês» e, enfim, reconhecido este trajeto eficaz, tornou-se sócio da Academia Real das Ciências e foi elevado ao pariato vitalício. Ordenado nas letras sob protetorado do velho Feliciano de Castilho, Chagas foi justamente o autor do

\footnotetext{
${ }^{15}$ Exceção, do ponto de vista ético, deve ser feita a casos (poucos) como os de Ramalho Ortigão e Sampaio Bruno, "publicistas» que aliaram (monárquico e tradicionalista, um; o outro, republicano e progressivo) a erudição e o gosto pelas letras, as artes e as ciências ao culto aristocrático da elite. Para além destes, o reduzido número estendeu-se aos que suicidaram, como Antero de Quental ou Trindade Coelho, num mal de século ou, melhor, de fim-de-século demissionário.
} 
Poema da Mocidade, em 1865, que imediatamente despoletou essa revolução intelectual conhecida por Questão Coimbrã ou polémica do Bom senso e bom gosto.

Ora, a entrada em cena da Geração de 70, para além do vigor crítico e a contundência polémica sobre a decadência ou crise do pensamento, trouxe consigo um combate ao intelectual instalado em que o homem de letras se convertera; no pano de fundo de uma querela literária, a si mesma (e longamente no tempo, aliás) se designou "a geração» - sintoma da necessidade de afirmação (a que a nomenclatura não era estranha) de uma nova e expurgada elite culta que procurou um novo estatuto intelectual capaz de substituir a vulgaridade, a banalização e a reprodução de gente e de valores que representava a "escola do elogio mútuo» dominada pelos "homens de letras» tradicionais. Desde o começo da polémica que Antero de Quental o afirmou:

O que se ataca na escola de Coimbra [...] não é uma opinião literária menos provada, uma conceção poética mais atrevida, um estilo ou uma ideia. Isso é o pretexto, apenas. Mas a guerra faz-se à independência irreverente de escritores, que entendem fazer por si o seu caminho (FERREIRA; MARINHO 1985: 235).

Passados os anos (brevíssimos) de fulgor do seu aparecimento, a chamada Geração de 70 (na sua maior parte) rendeu-se progressivamente ao "vencidismo", conforme a sintomática designação de Vencidos da Vida que os seus protagonistas a si mesmos se deram, rodeados de aristocratas de cepa e rodeando o poder num convívio áulico. Por certo não convencidos, mas vencidos no palco intelectual da época, restou-lhes insistir na aristocracia do espírito; ao fundar a Revista de Portugal, em 1889, Eça de Queirós insistia nostalgicamente no perfil desse título como revista da "geração", nomenclatura genérica ou imprecisa de uma elite intelectual a que caberia, no mínimo, um lugar entre os melhores espíritos europeus.

Dos tempos da "geração", mas sem a ela ter pertencido, ao menos formal ou explicitamente, um artista de pincel deu o primeiro sinal de transgressão do estatuto reservado aos "homens de letras»: trata-se de Rafael Bordalo Pinheiro que, em 1871, enquanto decorriam as Conferências do Casino organizadas pelos escritores da Geração de 70 , publicou a sua "conferência» gráfica numa prancha em quadradinhos ${ }^{16}$. Para além do seu enorme talento artístico, Bordalo trazia a novidade da eficácia de um discurso artístico no espaço público, explorando o prisma visual da comunicação: sem reclamar propriamente um estatuto diferenciado, num discurso alinhado pela estética realista de crítica político-social, abriu no entanto, pela primeira vez, a porta à afirmação social do artista e ao seu reconhecimento público.

Contemporâneos do Realismo em Portugal, os poetas parnasianos, a partir do jornal $A$ Folha dirigido entre 1868 e 1873 por João Penha, não tiveram força para afirmar na época a "arte pela arte», mesmo nas suas aproximaçóes impressionistas, como em Cesário Verde. Foi o último Eça de Queirós - esse que se revia no papel de «cenobita» no mundo-à-parte de "uma vida delirante e grandiosa", confidenciou a Oliveira Martins (QUEIRÓS 1986: 2; 312-313) - quem sacralizou a figura do artista, despindo-se da pretensão a exercer uma influência exterior e refugiando-se na sua arte, mesmo em

${ }^{16}$ Referimo-nos à prancha no 8 do álbum $A$ Berlinda (PINHEIRO 1870). 
estilo de vida de artista, como campo simbólico diferenciado das restantes elites, mais depurado e elitista. Seriam os "touristes da inteligência", dizia o biógrafo de Fradique Mendes (QUEIRÓS 2014: 147). Mas seria necessário esperar pela geração modernista da revista Orfeu, em 1915, para assistir à consagraçáo desse artista, avesso a todo o academismo das letras e das artes tanto quanto alheado das massas. E, curiosamente, em 1915 desapareciam, como que marcando o fim de uma época, Ramalho Ortigão, Sampaio Bruno e França Borges, os três últimos grandes publicistas.

Referências e bibliografia

ADORNO, Theodor - Sobre a Indústria da Cultura. Org. de A. Sousa Ribeiro. Coimbra: Angelus Novus, 2003. 198 p. ISBN 972-8827-20-2.

BALLE, Francis - Médias et sociétés, de Gutenberg à internet. 8ª ed. Paris: Monchrétien, 1997. 821 p. ISBN 2-7076-0783-5.

BOURDIEU, Pierre - "Une révolution conservatrice dans l'édition». Actes de la Recherche en Sciences Sociales. Paris. ISSN 0335-5322 [em linha]. No 126-127 (mar. 1999), p. 3-28. Disponível em <https://www.persee.fr/doc/arss_0335-5322_1999_num_126_1_3278>.

BRANCO, Camilo Castelo - Dispersos. Compil. e notas de Júlio Dias da Costa. Vol. I. Coimbra: Imprensa da Universidade, 1924. 589 p.

BRUNO, Sampaio - Os Modernos Publicistas Portugueses. Porto: Chardron, 1906. XVI, 425 p.

CHALABY, Jean - "O Jornalismo como invenção anglo-americana. Comparaçáo entre o desenvolvimento do jornalismo francês e anglo-americano (1830-1920)». Media \& Jornalismo. Coimbra: Minerva. ISSN 1645-5681. A. 2, n.o 3 (out.-inv. 2003). p. 29-50.

CHARLE, Christophe - Le Siècle de la Presse (1830-1939). Paris: Seuil, 2004. 399 p. ISBN 2-02-036174-4.

- Les intellectuels en Europe au XIXe siècle. Essai d'histoire comparée. 2a ed. Paris: Seuil, 2001, 452 p. ISBN 2-02-050050-7.

— - Naissance des «Intellectuels». 1880-1900. Paris: Minuit, 1990. 271 p. ISBN 2-7073-1325-4. - La Crise Littéraire à l'Époque du Naturalisme. Paris: Presse de l'École Normale Supérieure, 1979. 207 p. ISBN 2-7288-0055-3.

CORDEIRO, Luciano - Livro de Critica: arte e literatura portuguesa de hoje. Porto: Tip. Lusitana, 1869. 319 p.

CORREIA, João C. - Jornalismo e Espaço Público. Covilhã: Universidade da Beira Interior, 1998. 186 p. ISBN 972-9209-59-6.

DELPORTE, Christian - Les Journalistes en France : 1880-1950. Paris: Seuil, 1999. 449 p. ISBN 2-02-023509-9.

- Histoire du Journalisme et des Journalistes en France (du XVII siècle à nos jours). Paris: P.U.F., 1995. 127 p. ISBN ISBN 2-13-046778-4.

DIAS, Luís Augusto Costa - «Personagens inventadas: jornalismo e ficção na I Grande Guerra mediática (1914-1918)». Mediapolis. Coimbra: IUC. ISSN 2183-5918. № 6 (2018), p. 41-59.

- Do claro busto de Minerva à dupla face de Jano, ou os anos dourados da imprensa. In GOUVEIA, Cristina (coord.) - Roque Gameiro na Imprensa. Amadora: Casa Roque Gameiro, 2017. ISBN 978-972-8284-84-8, p. 7-17. 
_ - «Imprensa e espaço Público»; «Jornalismo moderno». In ROLLO, Maria Fernanda (coord.) - Dicionário de História da I República e do Republicanismo. Vol. II. Lisboa: Assembleia da República, 2014. ISBN 978-972-556-558-2, p. 370-373. p. 539-541.

_ - «Elites intelectuais». In ROLLO, Maria Fernanda (coord.) - Dicionário de História da I República e do Republicanismo. Vol. I. Lisboa: Assembleia da República, 2013. ISBN 978972-556-557-5. p. 1114-17.

— - No século do povo: a perspetiva liberal e romântica de Garrett e Herculano. In NEVES, José (coord.) - Como se Faz um Povo. Lisboa: Tinta da China / Fundaçáa EDP, 2010. ISBN 978-989-671-040-8. p. 85-92.

— - «O papel do impresso. A imprensa e a transformação do espaço público em Portugal (último quartel do século XIX - primeiro quartel do século xx)». Estudos do Século XX. Coimbra: IUC. ISSN 1645-3530. N. ${ }^{\circ} 7$ (2007) p. 307-317.

DIAZ, Brigitte - Stendhal face à la presse de son temps. In THERENTY, Marie-Ève; VAILLANT, Alain (dir.) - Presse et Plumes : journalisme et littérature au XIX ${ }^{e}$ siècle. Paris: Nouveau Monde, 2004. ISBN 2-84736-045-X. p. 17-29.

DIAZ, José-Luis - «L'esprit sous presse. Le journal et le journaliste selon la littérature panoramique». In THERENTY, Marie-Ève; VAILLANT, Alain (dir.) - Presse et plumes: journalisme et littérature au XIXe siècle. Paris: Nouveau Monde, 2004. ISBN 2-84736-045-X. p. 31-50.

DIOGO, Américo Lindeza; SILVESTRE, Osvaldo - Les Tours du Monde de Fradique Mendes. A roda da história e a volta da manivela. Sintra: Câmara Municipal, 1993. 148 p. Dep. Legal PT - 66556/93.

- O Espectro. Dir.: [António Rodrigues Sampaio]. Lisboa, 1 (16 dez. 1846) - 63 (3 jul. 1847) [nova ed. Lisboa: Tip. Diário da Manhă, 1880].

FERENCZI, Thomas - L'Invention du Journalisme en France. Naissance de la presse moderne à la fin du XIX siècle. Paris: Plon, 1993. 275 p. ISBN 2-259-02605-2.

FERNANDES, Paulo Jorge - Mariano Cirilo de Carvalho. $O$ "poder oculto" do liberalismo progressista (1876-1892). Lisboa: Texto Editores, 2010. 478 p. ISBN 978-972-47-4158-1.

FERREIRA, Alberto; MARINHO, Maria José (ed.) - Bom Senso e Bom Gosto. A Questão Coimbrã. Vol. 1. Lisboa: IN-CM, 1985. 646 p. Dep. Legal 35318-X-85 PT.

GARRETT, Almeida - Doutrinaçâo Liberal. Sel. Textos, introd. e notas de Luís Augusto Costa Dias. Lisboa: Alfa, 1990. 163 p. Dep. Legal 43225/91 PT.

HERCULANO, Alexandre - «Da propriedade literária e da recente Convenção com França». In Opúsculos. Org., introd.e notas de Jorge Custódio e José Manuel Garcia. Vol. I. Porto (imp.): Presença, 1982. p. 221-274.

KALIFA, Dominique - La Culture de Masse en France. 1860-1930. Paris: La Découverte, 2001. 122 p. ISBN 2-7071-3515-1.

KALIFA, Dominique [et al.] (dir.) - La Civilisation du Journal. Histoire culturelle et littéraire de la presse française au XIXe siècle. Paris: Nouveau Monde, 2011. 1762 p. ISBN 978-284736-543-6.

LOURENÇO, A. Apolinário - «De Fradique Mendes a Fernando Pessoa. A aventura interminável», Cadernos de Literatura. Coimbra: C.L.P. / I.N.I.C. Dep. Legal -2895/83 . N.o 25 (Dez. 1986). p. 45-52. 
MENDONÇA, A. P. Lopes de - Memórias de Literatura Contemporânea. Lisboa: Tip. do Panorama, 1855. 388 p.

MIRANDA, Paula Cristina - As Origens da Imprensa de Massa em Portugal: o Diário de Notícias (1864-1889). Dissertação de Mestrado em Estudos Históricos Europeus. Évora: Universidade de Évora, 2002. Polic. 305 p.

PEIXINHO, Ana Teresa - "Cânone realista e discurso de imprensa». In LOURENÇO, António Apolinário et al (dir.). O Século do Romance. Realismo e Naturalismo na Ficção Oitocentista. Coimbra: Centro de Literatura Portuguesa, 2013. ISBN 978-972-9126-28-4. p. 191-208.

— - A Epistolaridade nos Textos de Imprensa de Eça de Queirós. Lisboa: Fundação Calouste Gulbenkian / F.C.T., 2011. 568 p. ISBN 978-972-31-1346-4.

PEIXINHO, Ana Teresa; DIAS, Luís Augusto Costa - «A cidade e as suas personagens em fim-de-século no quadro de emergência de uma cultura urbana de massas em Portugal». Mediapolis. Coimbra: IUC. ISSN 2183-5918. N. 1 (1.o sem. 2015) p. 91-105.

PEREIRA, José Carlos Seabra - «Do Fim-de-Século ao Modernismo». In REIS, Carlos (dir.) - História Crítica da Literatura Portuguesa. Vol. 7. Lisboa: Verbo, 1995. 460 p. ISBN $972-$ 22-2473-5.

- - O Neo-Romantismo na Literatura Portuguesa. 1900-1925. Tese de Doutoramento, polic., Coimbra: FLUC, 1999.

PIEDADE, Ana Nascimento - Fradiquismo e Modernidade no último Eça, Lisboa: IN-CM, 2003. X, 332 p. ISBN 972-27-1157-1.

SERPA, António de - Poesias. Lisboa: Tip. da Revista Popular, 1851. 233 p.

PINHEIRO, Rafael Bordalo - A Berlinda: reproduçôes dum álbum humorístico ao correr do lápis. Lisboa: s.n., 1870 [ediçáa fac-similada, Lisboa: Biblioteca Nacional de Portugal, 2005. 8 f. desdobradas. Dep. Legal PT - 232837/05. Disponível em <http://purl.pt/23524/1/1385504_ PDF/1385504_0000_tE.pdf >].

QUEIRÓS, Eça de - A Correspondência de Fradique Mendes. Edição Crítica de Carlos Reis, Irene Fialho, Maria João Simões. Lisboa: INCM, 2014. 436 p. ISBN 978-972-27-2085-4.

- Cartas Públicas. Edição Crítica de Ana Teresa Peixinho. Lisboa: INCM, 2009. 239 p. ISBN 978-972-27-1800-4.

— - Textos de Imprensa IV (da Gazeta de Notícias). Edição Crítica de Elza Miné e Neuma Cavalcante. Lisboa: INCM, 2002. 685 p. ISBN 972-27-1125-3.

- Textos de Imprensa VI (da Revista de Portugal). Ediçâo Crítica de Helena Santana. Lisboa, INCM, 1995. 147 p., 4 f. ISBN 972-27-0718-3.

- Correspondência. Org. Guilherme de Castilho. 2 vols. Lisboa: IN-CM, 1983. 640; 622 p. Dep. Legal PT - 2622-83.

— - «Uma circular de E. Q.». In ANDRADE, M. - «Eça de Queiroz e a Revista de Portugal». Ocidente, Lisboa: Edição de Álvaro Pinto. Suplemento ao Vol. XLIV, No 177 (1953) p. 30.

RAFAEL, Gina Guedes; SANTOS, Manuela (org.) - Jornais e Revistas Portugueses do Século XIX [catálogo]. 2 vols. Lisboa: Biblioteca Nacional, 2001. 480; 432 p. ISBN 972-565-229-0. ISBN 972-565-314-9.

REIS, Carlos - Estudos Queirosianos. Ensaios sobre Eça de Queirós e a sua obra. Lisboa: Presença, 1999. 194 p. ISBN 972-23-2473-X.

RODRÍGUEZ MARTÍNEZ, Ruth - «Balzac, una visión crítica y contemporánea del periodismo». Estudios sobre el Mensaje Periodistico. Madrid: Universidade Complutense de Madrid. ISSN 
1134-1629. Vol. 12 (2006). p. 443-455. Disponível em <http://revistas.ucm.es/index.php/ ESMP/article/view/ESMP0606110443A/12382>.

RODRIGUES, Ernesto - O Mágico Folhetim. Literatura e Jornalismo em Portugal. 1. a ed. Lisboa: Editorial Notícias, 1998. 496 p. ISBN 978-972-46-0954-6.

SANTOS, Maria de Lurdes Lima dos - Intelectuais Portugueses na Primeira Metade de Oitocentos. Lisboa: Presença, 1988. 356 p. Dep. Legal - 21832.

TENGARRINHA, José - História da Imprensa Periódica Portuguesa. 2.a ed. rev. Lisboa: Caminho, 1989. 352 p. ISBN 972-21-0396-2.

THÉRENTY, Marie-Ève; VAILLANT, Alain - 1836, l'an I de l'ère médiatique. Paris: Nouveau Monde, 2001. 388 p. ISBN 2-84736-002-6.

VENÂNCIO, Fernando - Conceçôes de Lingua Literária em Portugal na Época de Castilho: 18351875. Tese de doutoramento, polic. Universidade de Amsterdão, 1995. 268 p. 